\title{
Comparison of Enzymatic Browning of Japanese Pear and Apple
}

\author{
Mie TsURUTANI, Masatsune MURATA* and Seiichi HommA \\ Department of Nutrition and Food Science, Ochanomizu University 2-1-1 Otsuka, Bunkyo-ku, Tokyo 112-8610, Japan
}

Received July 22, 2000; Accepted September 8, 2000

\begin{abstract}
When Japanese pear and apple are cut, the section of Japanese pear does not turn brown as readily as apple, although both fruits belong to the same family. Here, the enzymatic browning of the two fruits is compared. The activity of polyphenol oxidase (PPO) of Japanese pear was higher than that of apple. The PPO of Japanese pear existed uniformly throughout the fruit, while the PPO of apple was localized around the core. The content of chlorogenic acid, $(+)$-catechin, and (-)-epicatechin in Japanese pear was much lower than in apple. When these polyphenols were added to Japanese pear juice, the juice turned as strong a brown color as apple juice. Therefore, the reason why Japanese pear does not turn brown as easily as apple is that the amount of substrate of PPO in the former is much less.
\end{abstract}

Keywords: apple (Malus x domestica), Japanese pear (Pyrus pyrifolia), enzymatic browning, polyphenol oxidase

Polyphenol oxidase (EC 1.10.3.1, PPO) is found in various kinds of plant and oxidizes polyphenols to their corresponding quinones. These quinones are further polymerized with quinones or amines to form brown pigments. PPO is thus responsible for the enzymatic browning. We often observe this browning in fruit and vegetables such as apples, bananas, and lettuce, and the regulation of the browning is an important aspect in food processing and preservation.

Both apple and Japanese pear are popular fruits in Japan and belong to the same family, Rosaceae. When we cut these fruits, we observe the browning of apple flesh, but seldom observe the browning of Japanese pear flesh.

In our studies on apple PPO and enzymatic browning, we have isolated chlorogenic acid oxidase as the major PPO in mature fruits of apple (Murata et al., 1992) and characterized the enzyme immunochemically (Murata et al., 1993). Apple PPO existed uniformly in immature apples and the browning happened uniformly on a cut section of these apples. On the other hand, the PPO was localized around the core in mature apples and browning also occurred around the core most densely on the cut section. Thus the localization of PPO in apple tissue corresponded well to that of the browning (Murata et al., 1995b). Apple PPO was mainly located in plastids in apple cells as true of other plant PPOs (Murata et al., 1997). Boss et al. (1995) and Haruta et al. (1998) have cloned apple PPO gene and shown that PPO had a transit peptide to plastids. Tono et al. (1986) isolated Japanese pear PPO and examined its properties. However, there is no comprehensively comparative information on enzymatic browning of apple and Japanese pear. In this study, we compare the enzymatic browning, PPO and phenolics of these fruits, and report the reason why Japanese pear does not turn brown as easily as apple.

\section{Materials and Methods \\ Materials Apple (Malus x domestica cv. Fuji) and Japa-}

* To whom correspondence should be addressed.

E-mail:murata@cc.ocha.ac.jp nese pear (Pyrus pyrifolia cv. Kosui) were purchased in a local market in Tokyo.

Measurement of the browning of Japanese pear and apple juices A cold Japanese pear or an apple was peeled, cored, weighed, and then homogenized with the same weight of cold distilled water in a juicer for $30 \mathrm{~s}$. The homogenate was incubated on a reciprocating shaker (about 100 oscillations/min; Yamato BT-46, Tokyo) at $30^{\circ} \mathrm{C}$ for $0,30,60 \mathrm{~min}$ and $24 \mathrm{~h}$. The same volume of a $4 \%$ metaphosphoric acid solution was then added to the Japanese pear or apple juice samples to stop the enzymatic reaction.

Reflectance measurements ( $L, a$, and $b$ values) were determined by a TC-3600 color difference meter (Tokyo-Denshoku, Tokyo) to evaluate the degree of browning. Saturation and color difference were respectively calculated as $\left(a^{2}+b^{2}\right)^{1 / 2}$ and $\left(\Delta L^{2}\right.$ $\left.+\Delta a^{2}+\Delta b^{2}\right)^{1 / 2}$ after $24 \mathrm{~h}$ of incubation, each measurement being taken three times.

Extraction of phenolics A cold Japanese pear or an apple was peeled, cored, weighed, and homogenized with about twice the weight of cold methanol in a juicer for $30 \mathrm{~s}$ and the juice shaken for $10 \mathrm{~min}$. The homogenate was filtered, and the residue was extracted twice by methanol in the same way. The combined filtrate was concentrated in vacuo, and an aliquot of the concentrate was used for determining total phenolics. The concentrate was further extracted by ethyl acetate three times, the extract being dried by $\mathrm{Na}_{2} \mathrm{SO}_{4}$ and concentrated in vacuo. The crude paste obtained was dissolved in methanol, passed through SepPak C18 (Waters/millipore, Milford, MA) and Chromatodisk (0.45 $\mu \mathrm{m}$, Kurabo, Osaka), and then subjected to HPLC. Five Japanese pear or apple extracts were prepared.

Polyphenol determination Total phenolics were determined according to the method of Weurman and Swain (1955), using the phenol reagent (Folin-Denis method). Chlorogenic acid was used as the standard. Chlorogenic acid, (+)-catechin, and $(-)$-epicatechin were determined by HPLC with a photodiode array detector. The HPLC system was as follows: pump, Hitachi L-6320 (Tokyo); column, YMC Pak R-ODS-5 (Yamamura, Kyoto; 4.6 i.d. $\times 250 \mathrm{~mm}$ ); detector, Hitachi L-4500 (240-380 nm 
wavelength); recorder, Hitachi D-2000 chromatointegrator; eluent, $\mathrm{CH}_{3} \mathrm{CN}$ and $5 \%$ aqueous acetic acid (4:96) for $10 \mathrm{~min}$ and a linear gradient from $(4: 96)$ to $(40: 60)$ for $40 \mathrm{~min}$; flow rate, $1.0 \mathrm{ml} / \mathrm{min}$. Each extract was measured twice.

Preparation of PPO from Japanese pear or apple A Japanese pear or an apple was peeled, cored, weighed, and then homogenized with twice the weight of cold acetone in a juicer for $30 \mathrm{~s}$, this whole procedure being conducted at $0-4^{\circ} \mathrm{C}$. The homogenate was filtered, and the residue was washed several times with cold acetone. The washed residue was dried in vacuo and stored as an acetone powder at $-20^{\circ} \mathrm{C}$ until it was used. Each acetone powder $(0.5 \mathrm{~g})$ was extracted with $20 \mathrm{ml}$ of a $0.1 \mathrm{M}$ $\mathrm{KH}_{2} \mathrm{HPO}_{4}$ buffer ( $\mathrm{pH} 7.2$ ) containing $1.0 \%$ Triton $\mathrm{X}-100$ by homogenizing with a mortar and pestle for $10 \mathrm{~min}$. After filtering, the residue was extracted again with $20 \mathrm{ml}$ of the buffer. The combined filtrate was centrifuged for $30 \mathrm{~min}$ at $12,000 \times \mathrm{g}$, and the supernatant was used as crude PPO. Five Japanese pears or apples were used for the preparation.

PPO activity and protein assay PPO activity was measured by the spectrophotometric method at $325 \mathrm{~nm}$ to detect chlorogenic acid as the substrate (Fujita \& Tono, 1988). The reaction solution consisted of $0.8 \mathrm{ml}$ of a McIlvaine buffer prepared by mixing $0.1 \mathrm{M}$ citric acid with $0.2 \mathrm{M} \mathrm{Na}_{2} \mathrm{HPO}_{4}$ (pH 4.0), $0.1 \mathrm{ml}$ of $0.5 \mathrm{mM}$ chlorogenic acid, and $0.1 \mathrm{ml}$ of the enzyme solution. A decrease in absorbance of 0.1 per min at $325 \mathrm{~nm}$ and $30^{\circ} \mathrm{C}$ is defined as 1 unit of PPO. Each measurement was take twice, and five fruits were analyzed. Protein was determined according to the Lowry method (Lowry et al., 1951) with bovine serum albumin as the standard.

Nitrocellulose tissue print Nitrocellulose tissue prints were done by following the method of Reid et al. (1990) as described previously (Murata et al., 1993). A Japanese pear or an apple was cut vertically. The surface of the section was washed with water or left unwashed, and then blotted onto a nitrocellulose membrane by finger pressure for $1 \mathrm{~min}$; the membrane had been soaked beforehand in a $10 \mathrm{mM}$ phosphate buffer. The membrane was stained for PPO or protein. PPO was immunochemically detected and proteins were stained with $1 \%$ Amido Black 10B solution. For immunostaining, the membrane was blocked with $5 \%$ skim milk, the primary antibody was diluted $1: 500$, and the anti-mouse $\operatorname{IgG}$ peroxidase conjugate was diluted $1: 1000$.

\section{Results and Discussion}

Comparison of browning of Japanese pear and apple Japanese pear or apple juices diluted with the same amount of water were prepared to estimate browning susceptibility, water being added to make the preparation of juice easier. The diluted juice was then incubated at $30^{\circ} \mathrm{C}$ with shaking, and the degree of browning was measured by a color difference meter. In the apple juice, the $b$ value, corresponding to yellow, increased with incubation (Fig. 1), while in the Japanese pear juice, the $a$ and $b$ values increased little. When the color differences of the two juices are compared after $30 \mathrm{~min}$ of incubation, the color difference of Japanese pear $(2.51 \pm 0.06)$ was only about $1 / 3$ that of apple $(9.17 \pm 0.30)$. Japanese pear did not turn brown as easily as apple.

Comparison of polyphenol oxidase (PPO) of Japanese pear and apple The Japanese pear PPO activity $(51.1 \pm 0.4 \mathrm{U} / \mathrm{mg}$ protein) was higher than that of apple $(21.2 \pm 2.0 \mathrm{U} / \mathrm{mg}$ protein). The same buffer solution was used for both fruits on the extraction and the reaction. Even considering the PPO activity assay, that of Japanese pear was greater and was enough for browning. Japanese pear PPO is immunochemically similar to apple PPO,

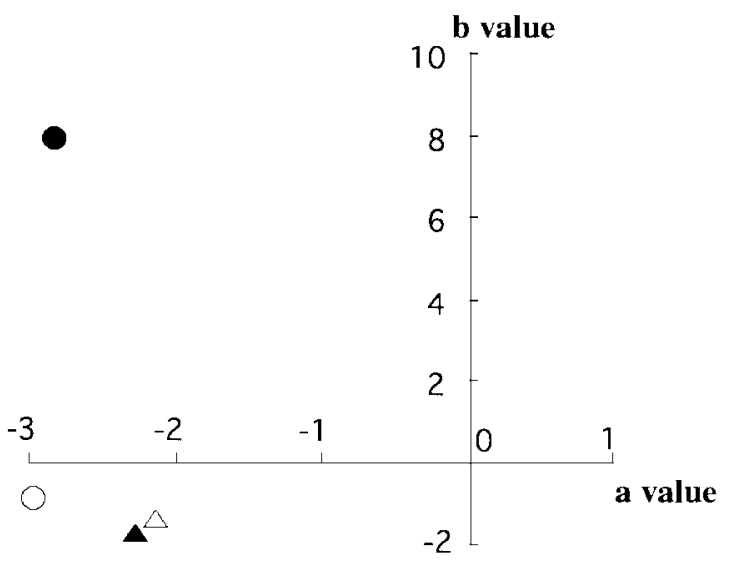

Fig. 1. Enzymatic browning of apple and Japanese pear juices. $\bigcirc$, apple (before incubation); $\bullet$, apple (30 min after incubation); $\triangle$, Japanese pear (before incubation); $\boldsymbol{\Lambda}$, Japanese pear (30 min after incubation).
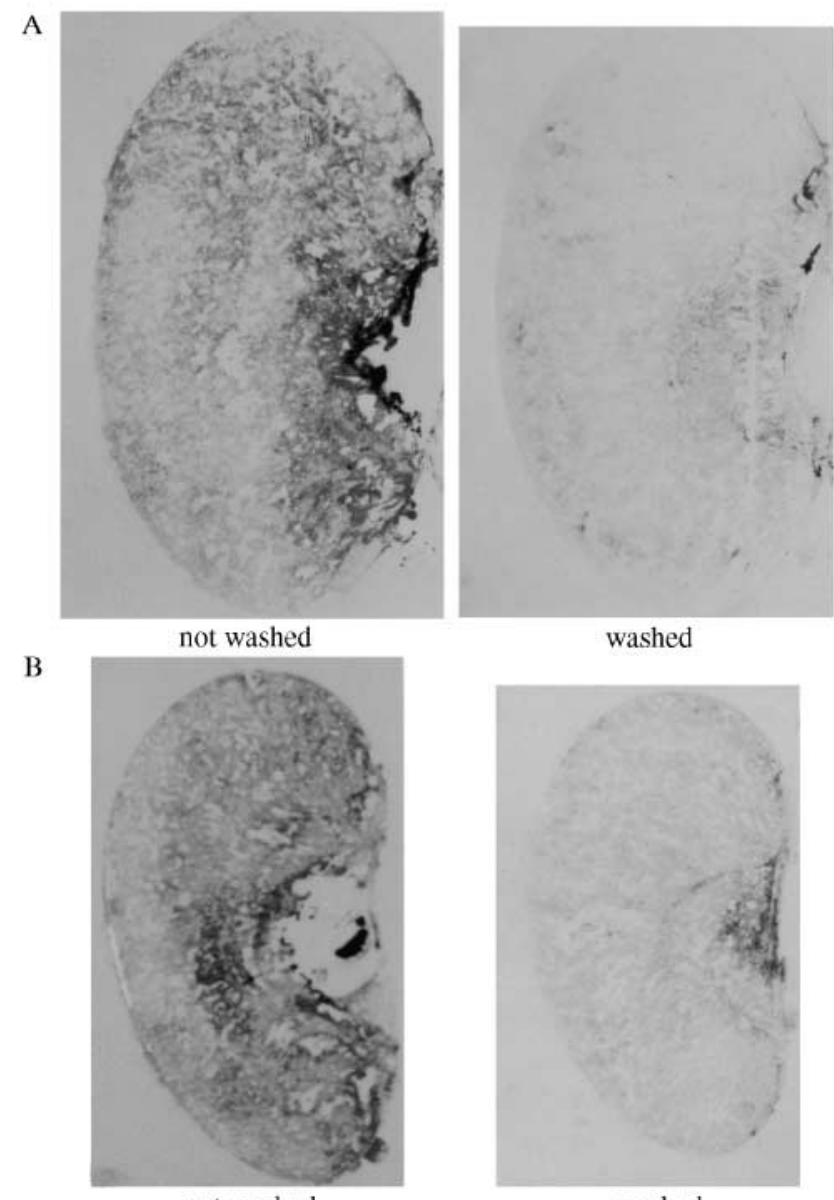

not washed

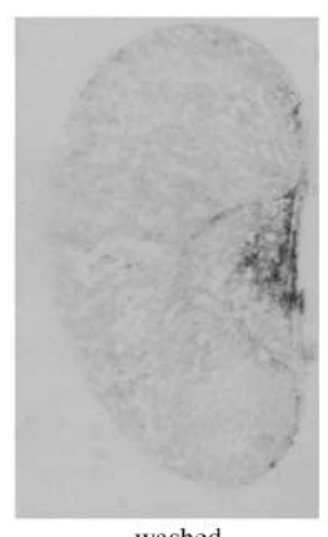

washed

Fig. 2. PPO (A) and protein (B) distribution in apple. An apple was cut vertically. A section washed with water or an unwashed section was blotted onto a nitrocellulose membrane with finger pressure. PPO or proteins were detected by anti-apple PPO antibody or Amido Black 10B, respectively. 


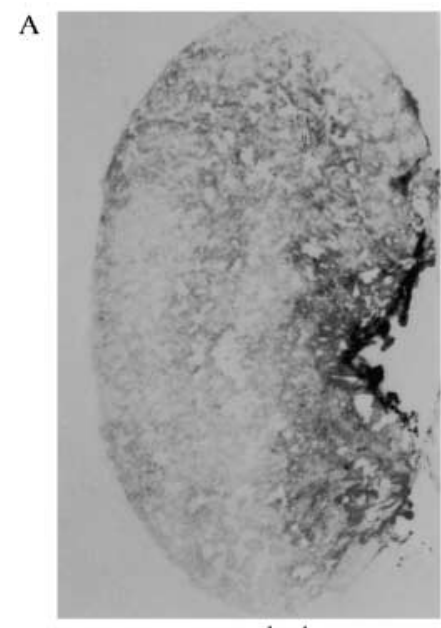

not washed

B

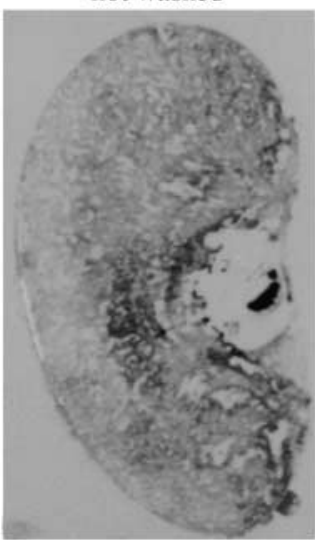

not washed

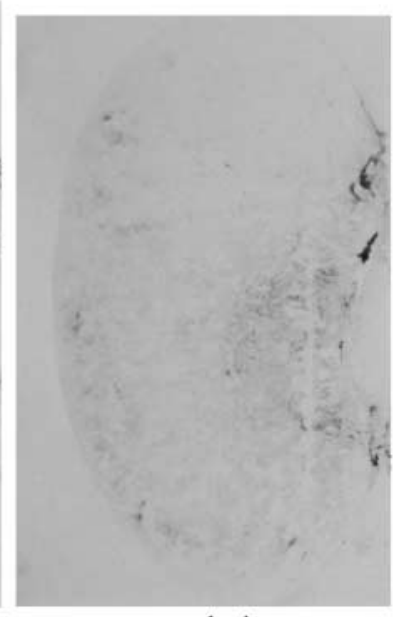

washed

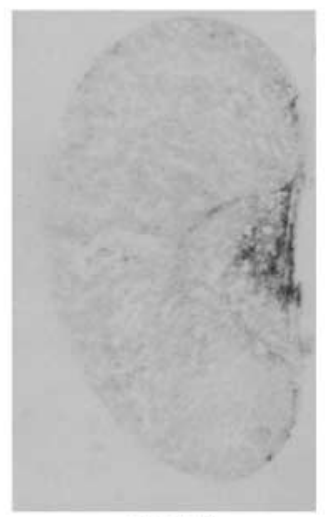

washed
Fig. 2. PPO (A) and protein (B) distribution in apple. An apple was cut vertically. A section washed with water or an unwashed section was blotted onto a nitrocellulose membrane with finger pressure. PPO or proteins were detected by anti-apple PPO antibody or Amido Black 10B, respectively.

and anti-apple PPO antibody could detect Japanese pear PPO (Haruta et al. 1999). The distribution of Japanese pear and apple PPOs was examined by the tissue print method using anti-apple PPO antibody. The membrane blotted with unwashed apple section was much more strongly stained than that blotted with the section washed with water (Fig. 2A), indicating that most of the apple PPO had been dissolved and washed out. Other proteins were also fairly well washed out (Fig. 2B). Although PPO was mainly located around the core in both cases, the unwashed apple section showed relatively uniform distribution of the enzyme. The Japanese pear sections, whether washed or not, were uniformly stained for PPO and proteins (Fig. 3). This result would be attributable to the difference in how PPO and other proteins exist in intact cells. Apple PPO was solubilized from plastids and denatured during maturation, and the active PPO was localized around the core (Murata et al., 1995b). These results suggest that the active PPO of Japanese pear is uniformly distributed, which was also supported by the fact that the section of Japanese pear uniformly turned brown when phenolics were sprayed on the cut section. $\mathrm{V}$

Comparison of polyphenols of Japanese pear and apple The amount of phenolics before and after browning of Japanese pear and apple juices was examined by the Folin-Denis method: total amounts of Japanese pear and apple before incuba-
Table 1. Total phenolics (mg/g flesh) of apple and Japanese pear juices before and after incubation.

\begin{tabular}{lcc}
\hline & \multicolumn{2}{c}{ Incubation time $(\mathrm{min})$} \\
\cline { 2 - 3 } & 0 & 30 \\
\hline Apple juice & $2.48 \pm 0.24$ & $1.35 \pm 0.16$ \\
Japanese pear juice & $0.50 \pm 0.03$ & $0.58 \pm 0.08$ \\
\hline
\end{tabular}

Values are shown as mean \pm standard deviation (five samples).

Table 2. Phenolics ( $\mu \mathrm{g} / \mathrm{g}$ flesh) of apple and Japanese pear juices.

\begin{tabular}{lcc}
\hline & Apple juice & Japanese pear juice \\
\hline Chlorogenic acid & $193.3 \pm 35.1$ & $0.9 \pm 0.2$ \\
(+)-catechin & $26.7 \pm 4.1$ & n.d. \\
(-)-epicatechin & $90.9 \pm 40.8$ & n.d. \\
\hline
\end{tabular}

Values are shown as mean \pm standard deviation (five samples). n.d., not detected.

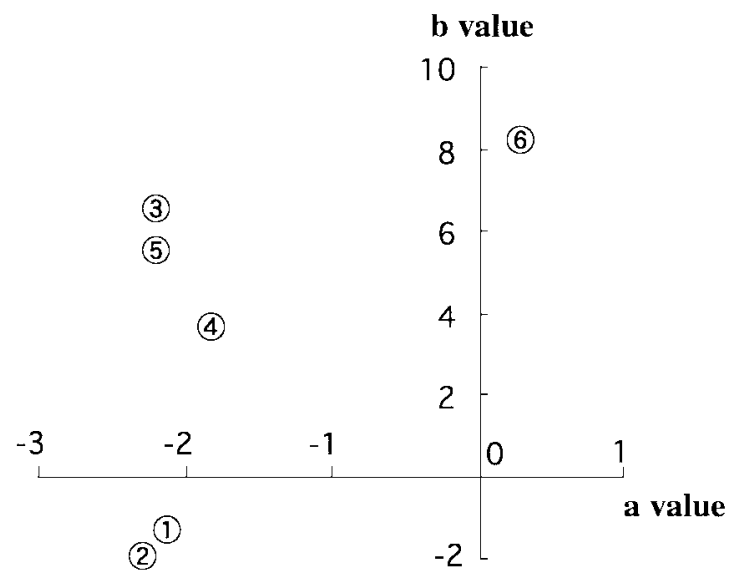

Fig. 4. Change in color of Japanese pear juice with polyphenols added. Polyphenols ( $0.2 \mathrm{mg} / \mathrm{g}$ flesh ) were added to Japanese pear juice and incubated at $30^{\circ} \mathrm{C}$ for $30 \mathrm{~min}$ (2)-(6)). (1), before incubation; (2), no addition; (3), (+)-catechin; (4), chlorogenic acid; (5), (-)-epicatechin; (6), (+)-catechin + chlorogenic acid $+(-)$-epicatechin.

tion were about $0.50 \pm 0.03 \mathrm{mg} / \mathrm{g}$ flesh and $2.48 \pm 0.24 \mathrm{mg} / \mathrm{g}$ flesh, respectively. Apple contained phenolics several times higher, but the amount was decreased by about half after $30 \mathrm{~min}$ of incubation, while that of Japanese pear did not change (Table 1). This result shows that about half amount the phenolics in apple juice was consumed by enzymatic browning. It did not seem that the total amount of phenolics in a crude extract estimated by the Folin-Denis method showed the amount of substrates of PPO, because no decrease in phenolics was observed in Japanese pear juice. Therefore, three polyphenols, chlorogenic acid, (-)-epicatechin, and (+)-catechin, were analyzed by HPLC. Chlorogenic acid was the major polyphenol in both Japanese pear and apple, although the amount in apple was 100 times higher (Table 2). Catechins are the major contributor to browning, because their oxidative products showed higher intensity of color than that of chlorogenic acid (Oszmianski \& Lee, 1990; Murata et al., 1995a). Catechins were hardly detected in Japanese pear. Fujita et al. (1999) reported that immature Japanese pear contained much more chlorogenic acid and catechins than mature fruits. This decline in phenolics during maturation was also observed in apple (Mosel \& Herrmann, 1974; Murata et al., 1995b) and pear 
(Mosel \& Herrmann, 1974).

Addition of polyphenols to Japanese pear If Japanese pear contained as much polyphenols as apple, it would brown as strongly as apple. As the content of the major polyphenol of apple, chlorogenic acid, was about $0.2 \mathrm{mg} / \mathrm{g}$ flesh, we added 0.2 $\mathrm{mg} / \mathrm{g}$ flesh of chlorogenic acid, $(+)$-catechin, or (-)-epicatechin to the Japanese pear juice, incubated it for $30 \mathrm{~min}$, and measured the degree of browning. By the addition of each polyphenol, $b$ value increased (Fig. 4). When the three polyphenols were added at the same time, the $a$ value was also increased, and browning was as strong as the juice of immature apple. Immature apple is easily browned, because it is rich in catechin (Murata et al., 1995b).

The regulation of apple browning is important in food processing and preservation. Some trials have been made to repress the expression of PPO to reduce the browning potential of apples (Murata et al., 2000). Our results suggest that apples containing less polyphenols show less browning potential.

In conclusion, Japanese pear does not contain enough polyphenols for enzymatic browning, although it does contain enough PPO. This is the main reason Japanese pear browns less easily than apple.

\section{References}

Boss, P.K., Gardner, R.C. Janssen, B.J. and Ross, S.P. (1995). An apple polyphenol oxidase cDNA is up-regulated in wounded tissues. Plant Mol. Biol., 27, 429-433.

Fujita, S. and Tono, T. (1988). Purification and some properties of polyphenol oxidase in eggplant (Solanum melongena). J. Agric. Food Chem., 46, 115-123.

Fujita, S., Kumamoto, M., Sonda, T., Yamamoto, M., Hayashi, N. and Ishimaru, K. (1999). Antioxidative activities of young fruit extracts of Japanese pear and Satsuma mandarin. J. Jpn. Assoc. Food Preserv. Sci., 25, 99-104.

Haruta, M., Murata, M., Hiraide, A., Hiroshi, K., Yamasaki, M., Sakuta, M., Shimizu, S. and Homma, S. (1998). Cloning genomic DNA encoding apple polyphenol oxidase and comparison of the gene product in Escherichia coli and in apple. Biosci. Biotechnol. Biochem., 62, 358-362.
Haruta, M., Murata, M., Kadokura, H. and Homma, S. (1999). Immunological and molecular comparison of polyphenol oxidase in Rosaceae fruit trees. Phytochemistry, 50, 1021-1025.

Lowry, O., Rosebrough, N.J., Farr, A.L. and Randall, R.J. (1951). Protein measurement with Folin phenol reagent. J. Biol. Chem., 193, 265-275.

Mosel, H.-D. and Herrmann, K. (1974). Changes in catechins and hydroxycinnamic acid derivatives during development of apples and pears. J. Sci. Food Agric., 25, 251-256.

Murata, M., Kurokami, C. and Homma, S. (1992). Purification and some properties of chlorogenic acid oxidase from apple (Malus pumila). Biosci. Biotechnol. Biochem., 56, 1705-1710.

Murata, M., Kurokami, C., Homma, S. and Matsuhashi, C. (1993). Immunochemical and immunohistochemical study of apple chlorogenic acid oxidase. J. Agric. Food Chem., 41, 1385-1390.

Murata, M., Noda, I. and Homma, S. (1995a). Enzymatic browning on the market. Relationship between browning, polyphenol content and polyphenol oxidase. J. Jpn. Soc. Food Sci. Technol., 42, 820-826.

Murata, M., Tsurutani, M., Tomita, M. and Homma, S. (1995b). Relationship between apple ripening and browning: Changes in polyphenol content and polyphenol oxidase. J. Agric. Food Chem., 43, $1115-1121$

Murata, M., Tsurutani, M., Hagiwara, S. and Homma, S. (1997). Subcellular location of polyphenol oxidase in apples. Biosci. Biotechnol. Biochem., 61, 1495-1499.

Murata, M., Haruta, M., Murai, N., Tanikawa, N., Nishimura, M., Homma, S. and Itoh, Y. (2000). Transgenic apple (Malus x domestica) shoot showing low browing potential. J. Agric. Food. Chem., 48, 5243-5248.

Oszmianski, J. and Lee, C.Y. (1990). Enzymatic oxidative reaction of catechin and chlorogenic acid in a model system. J. Agric. Food Chem., 38, 1202-1204.

Reid, P.D., del Campillo, E. and Lewis, N. L. (1990). Anatomical changes and immunolocalization of cellulase during abscission as observed on nitrocellulose tissue prints. Plant Physiol., 93, 160165.

Tono, T., Fujita, S., Kaesaki, S. and Li, Z. (1986). Purification and high L-epicatechinoxidase activity in polyphenol oxidase of Japanese pear. Nippon Nogeikagaku Kaishi, 60, 705-712 (in Japanese).

Weurman, C. and Swain, T. (1955). Changes in the enzymatic browning of Bramley's seedling apples during the development. J. Sci. Food Agric., 6, 186-192. 